duce analytical errors. Changing from one stand to the other, which requires only 1 to $2 \mathrm{~s}$, eliminates this source of error. Every sample is pneumatically clamped on the spark stand, so the spark gap width is very reproducible and rapid sample handling is possible.

The sensitivity of the photomultipliers can be adjusted very simply. Coarse step printed circuit boards make it possible either to select one of ten sensitivities by relocating a wire or to choose new sensitivities for each of the five analytical programmes, thereby increasing the versatility of the system. By means of the computer, five fixed analytical programmes can be stored in the system. These, in turn, can be divided into any number of subprogrammes by means of punched paper tape. Thus, even in case of complex high-alloyed materials, examination becomes possible.

Manual operation of this system is extremely simple. Introduction of the sample, selection of the programme and actuation of the starter button are the only operating steps which are carried out by the operator; calculations and printout of the results in per cent by weight are carried out automatically. Even for complex, high-alloy materials results are within the limit of conventional standard deviations-but are obtained within about $1 \mathrm{~s}$. WOLFGANG THOMICH

\title{
CORRESPONDENCE
}

\section{Dingle's Answer}

SIR,-While I accept and appreciate the apology on page 315 of this issue for the charge of dishonesty made in Professor Ziman's review ${ }^{1}$ of my book, Science at the Crossroads, the circumstances are such that a further statement from me is called for so that the matter shall be rightly understood. It would, of course, be possible for me to have made false statements quite honestly, and readers of Nature might well infer, in the absence of comment from me, that such was the fact that had merely been expressed in the review by the wrong word. It is particularly necessary for me to remove that impression because the description of the book given by Professor Ziman, which has already been independently described in Nature as "admirable", fails to make clear that its whole significance depends on the truth of its factual statements. "My purpose throughout", I wrote (page 19), "is not to indict but to inform, and let the facts bring whatever indictment is necessary." I cannot, therefore, justifiably allow any doubt to exist of the trustworthiness of those facts, for all of which I possess conclusive evidence.

This clarification is the more necessary because Ziman's opening sentence ("This is Professor Dingle's account of his attempt to persuade the scientific community that the theory of relativity is wrong and should be repudiated") must almost certainly suggest that to give such an account was the main, if not the only, purpose of the book. This would be quite false. I certainly should not have written it as a piece of autobiography, or even to try again to persuade the scientific community of anything. wrote it, with great reluctance, only after 13 years of continuous effort in that direction had convinced me that further effort was useless, and it was because the reason for my failure seemed to me so ominous, both for the future of science and for the effect of scientific research on public welfare generally, that I had a moral obligation to make the whole facts known, free from my interpretation of them, and to leave readers to form their own judgment of what they implied. I referred in the preface (page 9) to my inability to obtain "the one essential desideratum of the whole exercise-plain evidence, through an answer to, or acceptance of, a very simple refutation of the immeasurably important special relativity theory, that the obligation to preserve strict integrity in science continues to be honoured", and I began the summing-up at the end (page 219) by saying "The primary and inescapable purpose of this book, which Part One attempts to fulfil, is to make known, to those with an in. defeasible right to the knowledge, the present state of the scientific world as revealed by its practice, and to bring it into comparison with what is generally believed, and implicitly trusted, to be its state as typically expressed by the late Sir Henry Dale. I leave the reader to judge the significance of the comparison for himself, and to estimate what the consequences are likely to be if the present degree of conformity continues." This purpose is continually stressed in the intervening pages.

To prevent further misunderstanding I must add that part 2 ("The Intellectual Issue") on which Professor Ziman does not comment, though of equal length to part 1 ("The Moral Issue"), is of relatively academic interest. It is my reading of the historical causes of the change of attitude of scientists to their work, and is, of course, open to free criticism which I have not the slightest desire to suppress. Part 1, being incontrovertibly factual, is open only to reflexion, leading to whatever action concerned readers may think it proper to take. Professor
Ziman's purported answer to my scientific "Question", which is the source and not the substance of part 1, has already been dealt with ${ }^{3}$.

$$
\text { Yours faithfully, }
$$
Herbert Dingle

\section{Purley, Surrey}

1 Ziman, J., Nature, 241, 143 (1973).

Ellis, G. F. R., Nature, 242, 143 (1973).

'Dingle, H., Nature, 242, 423 (1973).

\section{Research Funding}

SIR,-While it may appear fruitless to object to yet another cutback in federal funding for education and science, I do wish to protest very strongly about the recent reduction in a little noticed but extremely important programme-the National Science Foundation Undergraduate Research Participation programme.

Under grants from this programme, undergraduate science students conduct independent research projects during the summer months. The most gifted and dedicated students are exposed to the literature and techniques of the field, and are given the opportunity to design and execute their own projects under the aegis of an experienced professor.

This will be the fourth summer that I have supervised such a programme in the Biology Department at Massachusetts Institute of Technology. It is noteworthy that all of the students in this programme have gone on either to graduate school in the biological sciences or to medical school. Many of these students, while still undergraduates, published papers on their research or presented papers at national meetings.

My own interest in scientific research was kindled by four summers' research while in college and high school. My colleague Dr David Baltimore, a leader in cancer research and the study of 
RNA tumour viruses, was first introduced to scientific research in NSF programmes. I could cite numerous similar examples from among the current leaders in virtually every field of scientific research.

This programme has been threatened several times with extinction. Funds for it were cut this year from $\$ 3.9$ million in 1972 (supporting 2,600 students) to $\$ 2.0$ million (supporting 1,300 students). The seriousness of this cut can be seen from the fact that, in all fields of the biological and medical sciences, and in all the colleges and universities in the nation, there will be space for only 308 students this year. Our own programme has been cut from 20 to 15 students. For these places we received over 160 applications and we were forced for lack of funds to reject many straight $A$ and other very qualified students.

The scientific leaders of the USA during the next two decades are the gifted undergraduates of today; it is these students who are now being discouraged from entering research careers in all fields of science because of reduc. tions of federal support in training and research funds at all levels. The NSFURP programme, in particular, plays a central role in attracting gifted people into research careers, and its demise may have profound effects on the production of future scientific leaders.

Yours faithfully, HARVEy F. Lodish

Department of Biology,

Massachusetts Institute of Technology, 77 Massachusetts Avenue, Cambridge, Massachusetts 02139

\section{Nobel Realpolitik}

SIR,-No doubt Eugene Garfield (Nature, 242, 485; 1973) is correct about the correlation of citation frequency and Nobel Prizes. Such is the Realpolitik of science. But this indicates little about the true scientific value of frequently cited articles, and almost nothing about the value of those less frequently cited.

The $S C I$ is a splendid bibliographic tool and may be a sociological tool as well. But I trust that the "rationale for thousands of infrequently cited journals" will not in fact be questioned merely on Dr Garfield's evidence. He should recall that Mendel's great paper was buried in an obscure journal, and Sir William Bragg's first seminal works rattled around ineffectually for a time in thenunknown Australian periodicals. There are quite a few other examples.

Thanks to SCI's Permuterm Subject Index such oversights need not now happen, but equally thanks to many infrequently-cited journals more really very good (and some really very bad) material gets into print. There is always the chance of another Mendel.

Yours faithfully, JAMES FRIDAY

The Royal Institution,

21 Albemarle Street,

London $W 1 X 4 B S$

\section{Unanswered Questions}

Sir,-One of your correspondents ${ }^{1}$ asks those who, like myself, have referred to "flaws" and "unanswered questions" in evolutionary thought if they can supply examples. We certainly canmany of them. For space reasons I will quote only three.

Only four years ago a Darwinist grudgingly admitted that "Though it is nearly a century (sic) since Darwin wrote his treatise On the Origin of Species, there are still a few weak points in the theory of evolution. Often evolution seems to have made huge jumps, leaving no traces of any intervening steps and no hint that anything but the complete system could have functioned at all"'.

It is surely incompatible with the scientific method to pretend that evolution is a proven fact, with these "huge jumps" unexplained. How did the whale evolve a complex nipple that enables it to suckle its young under water? This complex organ would have been worse than useless until it was fully developed, or Whale Junior would have received a mouthful of seawater instead of milk.

How did the giraffe evolve a long neck without first evolving the complex hydraulic control system that maintains an acceptable blood pressure in his brain whilst he lowers and raises his head? Or did he evolve his unique mechanism for regulating cerebral blood pressure before he evolved his long neck-and if so, how could such motiveless evolution have occurred?

Anadromous fish, grey whales and some species of migrating birds share an ability to find their way to an exact spot thousands of miles away. It is doubtful whether a submarine could equal their performance without the aid of shorebased radio beacons, even using today's highly sophisticated computer-based navigational systems. How did creatures so widely separated in the evolutionary tree as birds, fishes and mammals, all evolve these extraordinary navigational mechanisms? The problem is compounded by the experimental evidence that the spatial distribution of various elements in the oceans, the Earth's magnetic field, and the position of the stars all play a part in the overall pheno. menon. Yet over geologic time these three parameters have been varying continuously; how, then, did these creatures evolve the ability to navigate against a moving datum?
If evolutionists would face these questions-and hundreds of others like them-honestly, they might both advance their branch of science and gain a little more respect for those Biblebelieving scientists who see no incompatibility between science and their Christian faith.

Finally, let me point out that your correspondent is a couple of generations out of date in his glib assertion that "any archaeologist, theologist or philosopher could tell them that many of the stories in the Bible are copied from the folktales of long-ago tribes more ancient than the Hebrews".

As I have shown at some length ${ }^{3}$ there are two schools of thought even amongst theologians about the accuracy of the Old Testament's historical narrativesand a considerable proportion of the world's leading archaeologists now regard these narratives as highly accurate records that are independent of, and in many cases precede, the legends of other ancient peoples. Yours faithfully,

\section{A. T. J. HAYWARD}

2 Wellington,

East Kilbride,

Glasgow G75 $8 R B$

${ }^{1}$ Angseeing, J. P. A., Nature, 242, 214 (1973).

2 Anonymous, New Scientist, December 11, $542(1969)$

${ }^{3}$ Hayward, A., God's Truth: A Scientist Shows Why it Makes Sense to Believe the Bible (Marshall Morgan and Scott, London, 1973).

\section{Errata}

The title to the article by M. Koltai and E. Mecs (Nature, 242, 525; 1973) should read "Inhibition of the Acute Inflammatory Response by Interferon Inducers", not ". . . Interferon Inhibitors".

IN the article "Sexual Behaviour and Sexual Motivation in the Female Rat" by R. F. Drewett (Nature, 242, 476; 1973) the first sentence in the last paragraph should read "Oestrus is associated with enhanced general activity but this seems to be independent of sexual receptivity".

IN the article "Sativin: an Induced Isoflavan from the Leaves of Medicago sativa L." by J. L. Ingham and R. L. Millar (Nature, 242, 125; 1973) paragraph 11 , line 14, should read "sativin" instead of "sativan" and paragraph 12 line 6, should read "lonchocarpan" instead of "lonchocarpin". The contents page entry should read "isoflavan" instead of "isoflavin" in both cases.

IN the article "Further Data on the Corsica-Sardinia Rotation" by F. Radicati di Brozolo and G. Giglia (Nature, 241, 389; 1973) paragraph 23, line 11, "lower" should read "upper" and "upper" should read "lower". 